\title{
Analysing the competency framework for all prescribers
}

Article

Accepted Version

Hall, K. ORCID: https://orcid.org/0000-0002-3830-9981 and Picton, C. (2020) Analysing the competency framework for all prescribers. Journal of Prescribing Practice, 2 (3). pp. 122128. ISSN 2631-8393 doi:

https://doi.org/10.12968/jprp.2020.2.3.122 Available at https://centaur.reading.ac.uk/98778/

It is advisable to refer to the publisher's version if you intend to cite from the work. See Guidance on citing.

Published version at: http://dx.doi.org/10.12968/jprp.2020.2.3.122

Identification Number/DOI: https://doi.org/10.12968/jprp.2020.2.3.122

$<$ https://doi.org/10.12968/jprp.2020.2.3.122>

Publisher: Mark Allen Group

All outputs in CentAUR are protected by Intellectual Property Rights law, including copyright law. Copyright and IPR is retained by the creators or other copyright holders. Terms and conditions for use of this material are defined in the End User Agreement.

www.reading.ac.uk/centaur

\section{CentAUR}


Central Archive at the University of Reading

Reading's research outputs online 


\section{Paper accepted by Journal of Prescribing Practice}

March 2020

\section{Authors}

1. Kat Hall

Associate Professor of Clinical Education and Director of the Centre for InterProfessional Postgraduate Education and Training, University of Reading

Lead Women's and Children's Pharmacist and Independent Prescriber, Imperial College Healthcare NHS Trust

2. Cathy Picton

Lead author, The Competency Framework for All Prescribers

\section{Title}

The Competency Framework for All Prescribers: its history and how it can support good prescribing practice

\section{Abstract}

An updated Competency Framework for All Prescribers was published in July 2016 and has been widely promoted as the tool for supporting prescribing practice. It can support practitioners to develop their practice and to demonstrate they are competent. However, for some, using it in practice remains a daunting task. In this article, the history and role of competency frameworks will be explored, detailing the background to the concept of competence in the NHS and how it has been described. The development of the competency framework for prescribing will be explored and examples given of how the updated Competency Framework for All Prescribers can be used in practice. Its use by all prescribers in all settings, will be illustrated in order to support future and current prescribers to develop their practice. 


\section{Competency frameworks and non-medical prescribing}

In late 1996 the Department of Health funded a project to introduce an organisation to promote high-quality and cost-effective prescribing by supporting professionals in the NHS; this project formed the National Prescribing Centre (NPC). Their work included a national programme to support the introduction of non-medical prescribing, of which one of their workstreams was to publish a range of profession specific prescribing competency frameworks from 2001. Following years of use in practice, collated experience and feedback, it became evident that the core set of competencies each profession associated with representing competent prescribing were essentially the same (Picton, 2015). In 2012, the NPC reviewed all the frameworks and published a common framework for all prescribers, called A Single Competency Framework for All Prescribers (NPC, 2012). This continues to be the terminology used by many non-medical prescribers to describe the framework they used in their studies and what supports them now. In 2011, the NPC became part of the National Institute for Health and Care Excellence (NICE) who tasked the Royal Pharmaceutical Society (RPS) with updating and managing the framework. The output of this project was the 2016 Competency Framework for All Prescribers. This new framework is designed to support education, organisations and practitioners themselves, to develop practice and promote competence. However, for some, using it in practice remains a daunting task. We have presented below the background to the concepts of competence and competency frameworks to support an understanding of how the framework came into existence and the theories that underpin this. We then use this theory to highlight different ways the framework can be used and propose a potential model for practitioners to use the framework. 


\section{Competence, competency frameworks and theory versus practice}

The National Health Service (NHS) published their Long Term Plan in 2019. It focusses on how the health service can develop over the next ten years with the advances in medicine, changing population health needs, increasing demand for health and care services, alongside the significant changes in delivering this via new digital means (NHS, 2019). The accompanying Interim NHS People Plan makes numerous references to competence and competency-based frameworks (NHS Improvement, 2019). Although the NHS has just celebrated its $70^{\text {th }}$ birthday, the use of competency frameworks within healthcare practice is more recent.

Competence as a term focuses on the capability of an individual to perform a role, a collection of knowledge, skills and behaviours, with the competencies being the quality of the capability demonstrated (Bates and Bruno, 2008). The concept of competency frameworks has developed over time, previously there were some that focused on the role rather than professional development (Bates and Bruno, 2008). The difficulties in assessing competence are discussed by Wass et al. (2001) who acknowledge that it is complex. They recommend that multiple approaches to review the indicators that form a competent practitioner are used to provide a holistic overview of performance. Competency frameworks are designed to consider how to bridge theory with clinical practice, providing a range of broad indicators of what would constitute a competent practitioner. They are not intended to provide a specific list of assessable targets, they are focussed on a practitioner's ability to do something, and to do it to an acceptable standard (ten Cate and Scheele, 2007). 
It is not possible to critique competence and competency frameworks in their entirety in this article. When considering how to focus on the development of practitioners in the workplace, to progress and demonstrate competence, it is necessary to consider the history of how competence and competency frameworks developed. This article will consider the work of Benner in the 1980s and Millers in the 1990s as a useful starting point.

\section{Theories related to competence and assessing theory versus practice}

Benner wrote about the increasing complexity of nursing practice and the increased responsibility this created, proposing a method was needed to differentiate levels of practice and support development to ensure staff retention (Benner, 1984). Benner had begun studying the recently published Dreyfus Model of Skills Acquisition, applied to nursing practice, to describe the complexity in situated performance and practice improvement. The Dreyfus Model was originally derived by two professors at the University of California to describe skill development unrelated to healthcare. It described a five-stage model of 'mental activities involved in directed skills acquisition' (Dreyfus and Dreyfus, 1980). Benner's work applied these five stages to nursing practice as summarised in Table 1.

In the 1990s, Miller acknowledged that when considering clinical education "no single assessment method can provide all the data required for judgement of anything so complex as the delivery of professional services" (Miller, 1990). Miller's work focused on defining a structure to illustrate how competence could be assessed, now frequently referred to simply as Miller's pyramid. The structure aimed to describe the transition from knowing something to knowing how to use that 
knowledge, then onto showing that the knowledge can be applied in simulated settings. Finally, at the top, doing something in clinical practice with real patients. The role of teaching and assessment were intertwined and Miller proposed that both should focus towards the top of the pyramid. Miller's work is now quoted in different ways for different purposes, the original pyramid focused on knowledge, competence, performance and action being different steps. It has evolved over time to be more focused on the steps that make up clinical competence, rather than competence being the second rung of applying knowledge. Some educational researchers have looked at different triangles such as segmented, inverted and nested (Al-Eraky, 2016). Cruess et al. (2016) proposed that a fifth step was needed to encompass professional identify formation, stating that there was evidence to support professional behaviours as being the goal for consistently good clinical practice. Others have added bottom layers such as knows about and heard of to represent an awareness (Peile, 2006). Despite the range of more recent additions to the pyramid, many practitioners continue to use the pyramid in its simplest form as exemplified in Figure 1. This approach is generic and can therefore be used by anyone supporting a practitioner to develop prescribing knowledge, skills and behaviours.

In the 1990's there were several publications that began to focus on concepts of competence in healthcare, one example being The Bristol Royal Infirmary Inquiry in 2001 which dedicated 30 pages to discussing 'Competent Healthcare Professionals' (The Bristol Royal Infirmary Inquiry, 2001). The educational work by academics such as Benner and Miller, alongside the recommendations from national publications, saw the more widespread use of assessments of competency and the 
development of competency frameworks for healthcare professionals. Health Education England (2016) state the benefits of competency frameworks are:

- creating a common structure for education and training

- enabling identification of individual learning needs

- supporting lifelong continuing professional development by focussing on development rather than a role

- facilitating movement of professionals between settings, promoting professional accountability

- supporting career progression

\section{Implications of historical theories to current practice}

Whilst the critique of Miller's work has focused largely on additions or clarifications to the pyramid, Benner's work is not without criticism. The research Benner has published recognises its limitations, and understanding the potential problems means the concepts can be applied to supporting development of prescribing skills acquisition. In turn, this provides an understanding of how to use Miller's ideas of progressive development towards competence. When considering Benner's work, the overall demonstration of knowledge, skills and behaviours must therefore all be viewed together. Firstly, it is important that the idea of expert practice is the primary focus, it is not about being an expert practitioner (Cash, 1995). Secondly, everything must be contextualised with a clear understanding that each situation has a specific perspective that needs to be subjectively interpreted by each participant (Altmann, 2007). This aligns to Miller's work promoting multiple assessments to build, develop and align together to show overall competence (Miller, 1990). The challenge of using Benner's work is that it can promote a traditional assessment approach to 
determining competence by a group of individuals with a recognised authority, but to be truly effective as healthcare practitioners we also need to be critically aware of our own performance (Altmann, 2007; Cash, 1995).

There are many examples of research that draws on Benner and Miller's work that are more recently published, each applying the theories in different ways or in different settings. However, much of the core concepts remain in use today in healthcare education, including prescribing education. For example, the General Pharmaceutical Council (GPhC) Standards for the education and training of pharmacist independent prescribers (GPhC, 2019) which uses Miller's pyramid, and the Foundation Programme Curriculum (UK Foundation Programme Office, 2016) which uses the principles of skills acquisition.

\section{The 2016 Competency Framework for All Prescribers}

Employing a review team who adopted the same methodology as the NPC, after extensive consultation and review, the 2016 Competency Framework for All Prescribers was published (RPS, 2016). The important role of this framework was recognised by its endorsement by multiple professional bodies and Royal Colleges. It is designed to be used by any prescriber at any point in their career because its premise is to bring all the professions together to harmonise the common aspects of responsibility within prescribing. It is therefore, as Benner recognised, the context within which it is applied that provides structure and support for individual prescribers in their own practice. 
The updated framework is formed of ten competencies, divided into two domains: the consultation and prescribing governance (see Figure 2). The change to two domains was deemed to be more intuitive in design compared to the 2012 framework, as it places the patient at the centre of all activities with the necessary governance sitting around all the components of prescribing. In addition, new indicators were introduced which reflected healthcare advances, for example remote prescribing, and new terminology, such as deprescribing and polypharmacy. In recognition that professionalism is a core attribute of all healthcare practitioners, the professionalism indicators were removed from the framework and now sit alongside it. In total there are now 65 indicators and seven professional behaviours in the framework. The full list of indicators is in the framework which is available on the RPS website.

In 2018, the Nursing and Midwifery Council (NMC) incorporated the framework in their new programme standards, requiring all programmes to be designed to fully deliver the competencies (NMC, 2018). In 2019, the Health and Care Professions Council (HCPC) similarly stated that programmes must ensure learners met the standards in the framework (HCPC, 2019).

\section{Example uses of the Competency Framework for All Prescribers}

There are many examples of using the framework available from the RPS on their website (https://www.rpharms.com/resources/frameworks/prescribing-competencyframework/how-the-framework-is-being-used), a few are discussed below grouped as educational, organisational and individual. 
Some of the earliest users of the 2016 framework were Universities, particularly those who had already included A Single Competency Framework for All Prescribers in their programmes of study and undertook a process of updating the framework in their documents. At the University of Reading the 2012 NPC framework was replaced by the updated framework in structuring professional learning portfolios which are used by prescribing students and their supervisors to identify individual learning needs and to evidence over time how they had met them. Using the same approach for all practitioners enrolled on the programme, whether supplementary, independent or independent prescribing conversion, has provided commonality and shared learning. It has also ensured the focus remains contextualised to their areas of practice. This example is replicated across other Universities as a means to structure and quality assure educational practices, but other prescribing examples have been recognised. For example, Betsi Cadwaladr University Health Board used the framework to design a teaching programme for fifth year medical undergraduates with positive pre and post assessment results (RPS, 2016).

Within employing organisations, many examples of using the framework in practice have been focussed on supporting new prescribers and to provide reassurance of governance processes. Primarily the framework serves as a portable tool that practitioners can use to identify learning needs as they grow into their expanded role. NHS Greater Glasgow and Clyde Addiction Services used it to define three levels of prescribers based on their qualification, experience and competence (RPS, 2016). City Health Care Partnership in Hull created a passport for all their non-medical prescribers to encourage ongoing reflection on the indicators, similarly 2 Gether Mental Health Trust provide new prescriber packs (RPS, 2016). Different employers 
have different processes for requiring evidence of competence, annual updates to personal formularies and audits of prescribing. Where employees are required to declare and/or submit evidence of competence, using the framework serves as a common, easily accessible, tool to frame the submission.

For individuals, the framework often represents a means to help them identify their ongoing learning needs, structure feedback they receive from colleagues and use this to demonstrate competence, whether to their employer (as above) or their professional body. Across professional statutory and regulatory bodies there are common tools that registrants need to complete to maintain their registration. Examples include reflective accounts, peer accounts, appraisals, CPD entries and submission of supporting information. Different practitioners find different barriers to their revalidation or CPD processes and there remains concern for many about how and when they will complete it (Underdown, 2017).

In an attempt to support prescribing practitioners with this we have suggested a potential process which is summarised in Figure 3. This process is based on the principles of reflective practice: to consider practice holistically, developing understanding and identifying learning needs to develop awareness of your own knowledge, skills and behaviours that form competence (Esterhuizen and HowatsonJones, 2019). We recognise it is not mapped to a reflective model or cycle as it aims to look at practice more broadly and therefore aligns more closely to Kolb's learning cycle applied to contexts of practice, a process similarly described by Morris (2019). Searching the internet for "How to use competency frameworks" produces multiple examples, some are specific to a framework and others are generic. The below 
aligns to experiences of using the framework in practice ourselves, and with others, and it mirrors guidance produced by the RPS on using their other competency frameworks (RPS, n.d.).

\section{An example process for reflecting on the framework for revalidation/CPD}

As a starting point you need to review the framework in your context: you, your level of qualification, your patients and your environment. Then collate any evidence you have of your performance (e.g. patient feedback, audit data) and consider it alongside any learning in the team (e.g. incident reports, audit data). It is useful at this stage to get feedback from your peers and managers/mentors on your performance, even if you do not work in a team regularly, because having external input can help benchmark your practice against others. Local and national networks can support networking and conversations between practitioners. This step is not an assessment nor is it a punitive exercise, it should be constructive and developmental.

Firstly, using the full framework available on the RPS website identify which of the 65 indicators you have lots of evidence you are doing well and consider them to be demonstrated (e.g. consistent feedback you build good relationships with patients may demonstrate behavioural indicator 3.5 at a top level against Miller's pyramid). Secondly, identify the indicators where you have evidence you are doing well but could improve your performance. This might be as you gain confidence but also could be as you develop your skills and are on the way to move towards proficient and expert (as per Table 1). For example, if there is an upcoming new generic 
medicine in your scope of practice and you need to make sure you know about applying the information holistically to meet behavioural indicator 4.4 .

Lastly, identify the indicators where you have evidence you need to improve your performance to be competent, where there are easy ways to gather additional evidence that might be mapped higher up Miller's pyramid, or no evidence to map and you are uncertain about your competence. This is not about failing, it is about improving your performance in a continually changing working environment. Examples could include things not specific to your practice but that affect you, such as a series of near misses in the team when remote prescribing for behavioural indicator 7.3. They could be more personal for example a colleague has told you about a new guideline you were not aware has been published for behavioural indicator 2.8. These should form the priority areas for you to focus on.

You can then take this information to decide your next steps, which could focus on a Personal Development Plan, a learning action plan, an agreement to undertake some mentoring with a colleague, or an identification of the need for formal training. The priority areas should be addressed first. Attempting to use a competency as an assessment marker can create a lot of work, the plan you decide should focus on activities that combine to show overall competence (ten Cate and Scheele, 2007). An example could be asking a colleague to observe your practice. You could also undertake reading within your scope of practice and apply the learning to interactions with your patients, or arrange attending a training event. These activities will support you to develop to make holistic judgements about patients that are safe (competent practice according to Benner) and in turn these form evidence of your overall 
knowledge, skills and behaviours which demonstrate competence (working towards the top level of Miller's pyramid).

\section{Future developments}

The Competency Framework for All Prescribers is due to be reviewed in 2020, the RPS will be asking prescribers for feedback on any proposed changes. It is important that prescribers from all professions and levels of prescribing contribute to this process to make it evidence based.

In December 2019 the RPS published the national Designated Prescribing Practitioner Competency Framework which will support the education of future prescribers (RPS, 2019). The recognition that annotated prescribers could also take on the important role of mentoring and supporting prescribers in training was a key step forward in showing their impact on healthcare. For any prescribers considering the role you will now need to demonstrate competence against both frameworks. The RPS will be hosting a series of launch events in early 2020 following which national and local educational sessions are likely to occur which interested practitioners can attend.

\section{Key points}

1. The introduction of competency frameworks in healthcare practice aims to support professionals develop in their roles

2. Competency frameworks to support non-medical prescribing were introduced in 2001 but in 2012 a single framework for all professions was published in 
recognition that the core competencies were essentially the same for all professional groups

3. A new updated Competency Framework for All Prescribers was published in 2016, hosted by the Royal Pharmaceutical Society

4. Organisations and providers of education can use the framework to structure and support future, new and experienced prescribers

5. Prescribers can use the framework to support their continuing professional development and revalidation/CPD submissions

6. Healthcare professionals can use the framework to model best practice in prescribing, whether related to a specific patient or general clinical practice

7. The new Competency Framework for Designated Prescribing Practitioners further supports experienced prescribers to supervise prescribers in training

\section{Reflective questions}

1. Which of the behavioural indicators do you feel least confident in demonstrating?

2. What feedback do your colleagues/mentors/mangers give you on your performance that you could map to the framework?

3. Who are the individuals you work with/national groups you could compare your practice with to help contextualise and benchmark your practice?

4. In the past month which experience as a prescriber has had the biggest impact on your practice and how have you learnt/changed your practice following it? 
5. Can you identify the attribute(s) demonstrated by other practitioners who you feel are proficient or expert, and how you could learn from them to develop your own practice towards expert?

\section{References}

Al-Eraky M and Marei, H. 2016. A fresh look at Miller's pyramid: assessment at the 'Is' and 'Do' levels. Med Educ. 50(12):1253-1257.

Altmann T K. 2007. An evaluation of the seminal work of Patricia Benner: Theory or philosophy? Contemp Nurse. 25(1/2):114-123.

Bates I and Bruno A. 2008. Competence in the global pharmacy workforce - a discussion paper. Int Pharm J. 1(23):30-33.

Benner P. 1984. From novice to expert: excellence and power in clinical nursing practice. Menlo Park, CA: Addison-Wesley.

Benner P, Tanner CA, Chesla CA. 2009. Expertise in nursing practice: caring, clinical judgement and ethics. $2^{\text {nd }}$ Edition. New York: Springer Publishing Company.

Cash K. 1995. Benner and expertise in nursing: a critique. IJNS. 32(6):527-534.

Cruess R, Cruess S, Setinert Y. 2016. Amending Miller's pyramid to include professional identity formation. Acad Med. 91(2):180-185. 
Dreyfus SE, Dreyfus HL. 1980. A five-stage model of the mental activities involved in directed skill acquisition. Operations Research Centre, University of California, Berkeley.

Esterhuizen P and Howatson-Jones L. 2019. Reflective practice in nursing. $4^{\text {th }}$ edition. Thousand Oaks: SAGE.

General Pharmaceutical Council. 2019. Standards for the education and training of pharmacist independent prescribers. Available from https://www.pharmacyregulation.org/sites/default/files/document/standards-for-theeducation-and-training-of-pharmacist-independent-prescribers-january-19.pdf.

Health and Care Professionals Council. 2019. Standards for prescribing. Available from https://www.hcpc-uk.org/globalassets/standards/standards-forprescribing/standards-for-prescribing2.pdf.

Health Education England. 2016. Care Navigation: A Competency Framework. Available from https://www.hee.nhs.uk/sites/default/files/documents/Care\%20Navigation\%20Compe tency\%20Framework Final.pdf.

Miller GE. 1990. Invited reviews: The assessment of clinical skills/competence/performance. Acad Med. 65(9):S63-S67. 
Morris T H. 2019. Experiential learning - a systematic review and revision of Kolb's model. Interactive Learning Environments. DOI: 10.1080/10494820.2019.1570279.

National Health Service. 2019. The NHS Long Term Plan. Version 1.2. Available from https://www.longtermplan.nhs.uk/wp-content/uploads/2019/08/nhs-long-termplan-version-1.2.pdf.

National Prescribing Centre. 2012. A single competency framework for all prescribers. Available from

https://www.webarchive.orhttps://www.webarchive.org.uk/wayback/archive/2014062 7111702/http://www.npc.nhs.uk/improving safety/improving quality/index.phpg.uk/w ayback/archive/20140627111702/http://www.npc.nhs.uk/improving safety/improving quality/index.php.

NHS Improvement. 2019. Interim NHS People Plan. Version 1. Available from https://www.longtermplan.nhs.uk/wp-content/uploads/2019/05/Interim-NHS-PeoplePlan June2019.pdf.

Nursing and Midwifery Council. 2018. Realising professionalism: Standards for education and training Part 3: Standards for prescribing programmes. Available from https://www.nmc.org.uk/globalassets/sitedocuments/educationstandards/programme-standards-prescribing.pdf.

Peile E. 2006. Commentary: knowing and knowing about. BMJ. 332(7542):645. 
Picton C. 2015. Competency framework for prescribers to be updated. Nurse Prescribing. 13(8):376.

Royal Pharmaceutical Society. 2016. A Competency Framework for all Prescribers. Available from

https://www.rpharms.com/Portals/0/RPS\%20document\%20library/Open\%20access/ Professional\%20standards/Prescribing\%20competency\%20framework/prescribingcompetency-framework.pdf?ver=2019-02-13-163215-030.

Royal Pharmaceutical Society. 2019. A Competency Framework for Designated Prescribing Practitioners. Available from https://www.rpharms.com/Portals/0/RPS\%20document\%20library/Open\%20access/ Professional\%20standards/DPP\%20Framework/DPP\%20competency\%20framewor k\%20Dec\%202019.pdf?ver=2019-12-18-150746-160.

Royal Pharmaceutical Society. n.d. APF Expert Professional Practice Cluster. Available from https://www.rpharms.com/Portals/0/RPS\%20document\%20library/Open\%20access/ Faculty/APF\%20-\%20Expert\%20Professional\%20Practice\%20cluster.pdf. ten Cate O, Scheele, F. 2007. Competency-Based Postgraduate Training: Can We Bridge the Gap between Theory and Clinical Practice? Acad Med. 82(6):542-547.

Thampy H, Willert E, Ramani S. 2019. Assessing clinical reasoning: targeting the higher levels of the pyramid. JGIM. 34(8):1631-1636. 
The Bristol Royal Infirmary Inquiry. 2001. The report of the public inquiry into children's heart surgery at the Bristol Royal Infirmary 1984-1995: learning from Bristol (Cm 5207). London: The Stationery Office.

UK Foundation Programme Office. 2016. The Foundation Programme Curriculum. Available from https://foundationprogramme.nhs.uk/wpcontent/uploads/sites/2/2019/11/FP Curriculum 2016 V2-1 0.pdf.

Underdown R. 2010. Revalidation makes us better nurses. Available from https://www.nurses.co.uk/nursing/blog/revalidation-makes-us-better-nurses/.

Wass V, Van der Vleuten C, Shatzer J and Jones, R. 2001. Assessment of clinical competence. Lancet. 357(9260):945-949.

\section{$\underline{\text { Keywords }}$}

Competence

Competency framework

Prescribing competencies

Competency Framework for All Prescribers

Royal Pharmaceutical Society

Revalidation 
Table 1 - Summary of Benner's work on clinical performance (Benner, 1984;

Benner et al., 2009)

\begin{tabular}{|c|c|c|}
\hline Stage & Description & Implications \\
\hline Novice & $\begin{array}{l}\text { No practice-based experience } \\
\text { Demonstrates inflexible and rule- } \\
\text { based behaviours focussed on the } \\
\text { process } \\
\text { Little or no experience-based } \\
\text { discretionary judgement applied to } \\
\text { patient care }\end{array}$ & $\begin{array}{l}\text { Individual needs supervision } \\
\text { for every task }\end{array}$ \\
\hline $\begin{array}{l}\text { Advanced } \\
\text { beginner }\end{array}$ & $\begin{array}{l}\text { Has practice-based experience } \\
\text { Performance is marginally } \\
\text { acceptable, but not considered } \\
\text { clinically competent } \\
\text { Demonstrates development of an } \\
\text { understanding of the meaningful } \\
\text { components } \\
\text { All components are treated equally, } \\
\text { does not demonstrate ability to set } \\
\text { priorities }\end{array}$ & $\begin{array}{l}\text { Individual needs supervision } \\
\text { for processes made up of } \\
\text { several tasks; may need } \\
\text { supervision for complex tasks }\end{array}$ \\
\hline Competent & $\begin{array}{l}\text { Can see each component as part of } \\
\text { a larger plan over time } \\
\text { Decision making is safe, but often } \\
\text { requires conscious effort }\end{array}$ & $\begin{array}{l}\text { Individual can make } \\
\text { judgements appropriately to } \\
\text { provide safe patient care }\end{array}$ \\
\hline Proficient & $\begin{array}{l}\text { Sees the holistic view of the } \\
\text { situation, rather than each } \\
\text { component separately } \\
\text { Demonstrates speed and flexibility in } \\
\text { delivering appropriately prioritised } \\
\text { patient care based on previous } \\
\text { experience } \\
\text { Decision making requires less } \\
\text { conscious effort }\end{array}$ & $\begin{array}{l}\text { Individual can safely work } \\
\text { outside the rules to aim for } \\
\text { person-centred care }\end{array}$ \\
\hline Expert & $\begin{array}{l}\text { Uses practice-based experience to } \\
\text { apply intuition and determine } \\
\text { components and the plan without } \\
\text { rules or guidelines } \\
\text { Identifies when things are not going } \\
\text { as expected to reapply analytical } \\
\text { skills }\end{array}$ & $\begin{array}{l}\text { Individual shows excellence in } \\
\text { clinical decision making } \\
\text { based on intuition }\end{array}$ \\
\hline
\end{tabular}




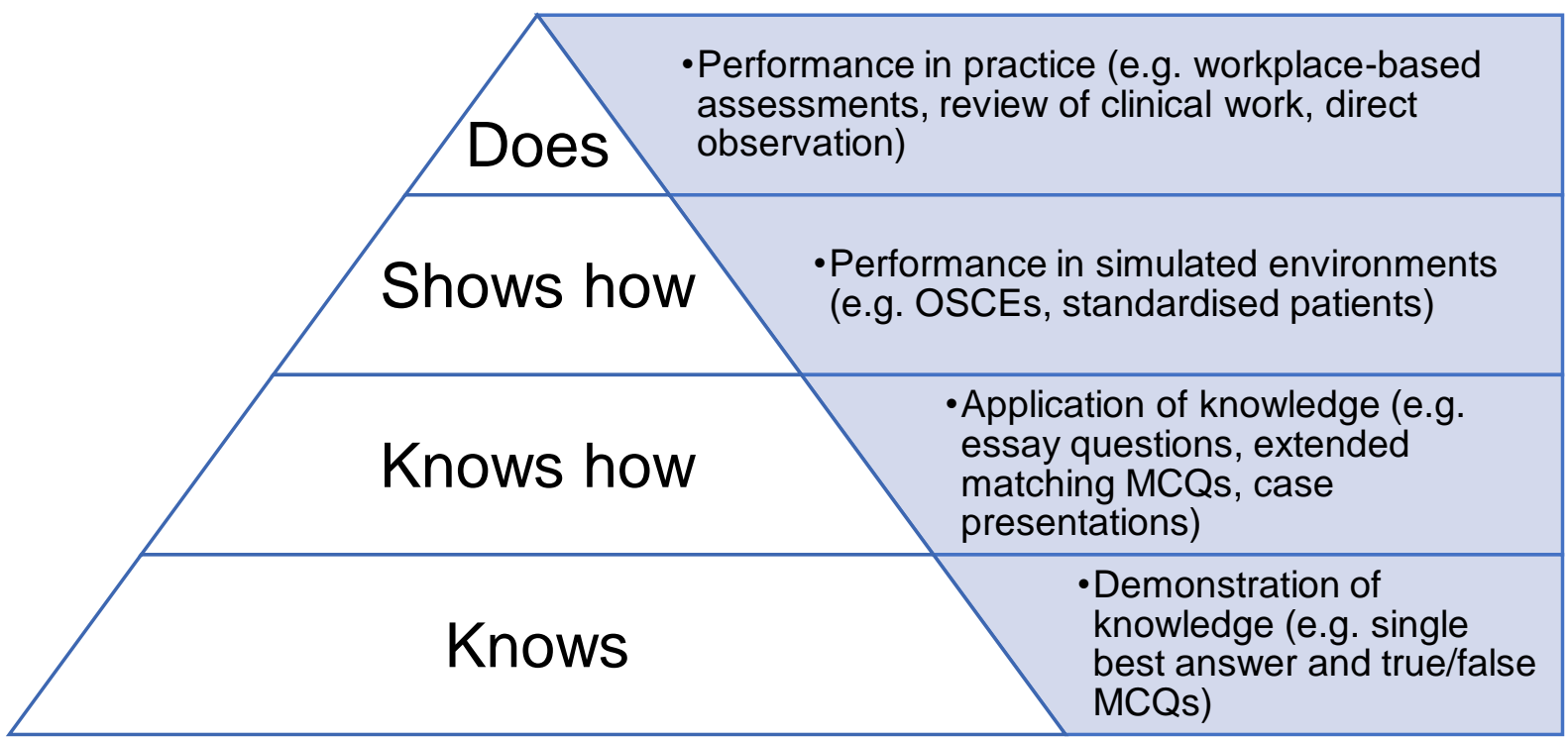

Figure 1 - Miller's Pyramid of Clinical Competence (adapted from Miller, 1990; Thampy et al., 2019; Wass, 2001) 


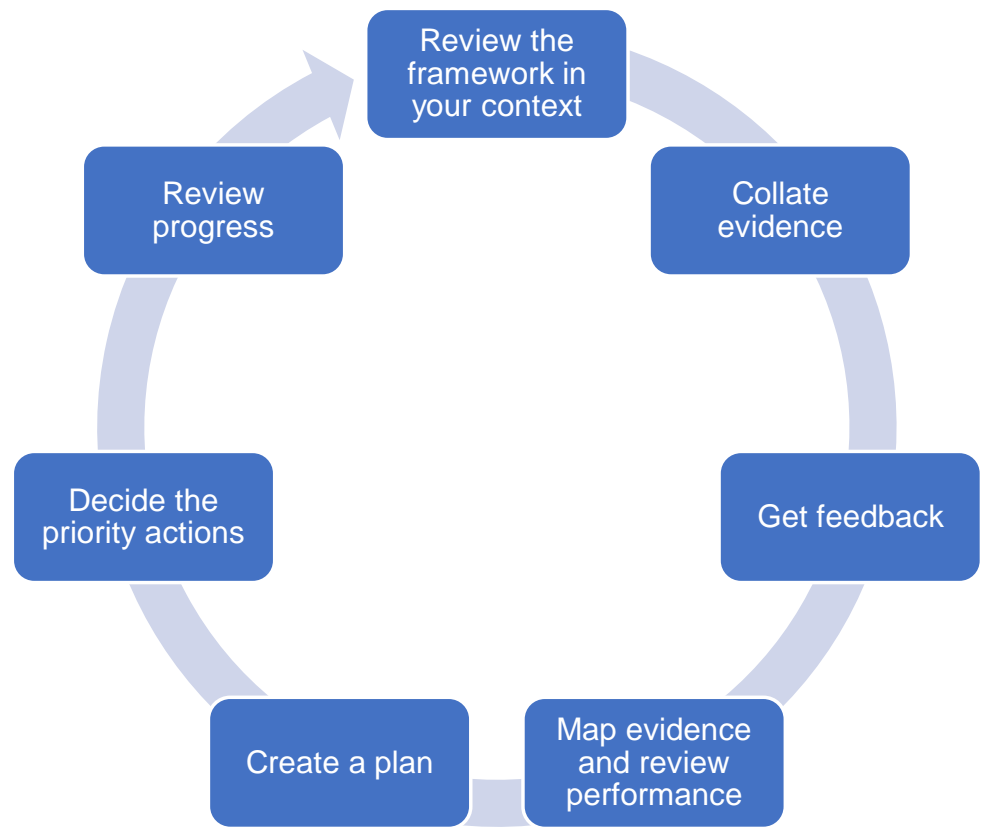

Figure 3 - Example process to reflect on the framework 